\title{
Estimation of Oxidative Stress Markers in Chronic Kidney Disease
}

\author{
Agnieszka Kuchta $^{a}$ Anastasis Pacanis ${ }^{a}$ Barbara Kortas-Stempak $^{a}$

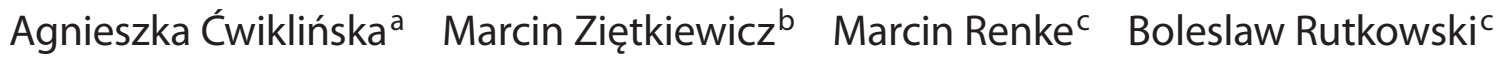 \\ Departments of a Clinical Chemistry, ${ }^{\mathrm{b}}$ Internal Diseases, Connective Tissue Diseases and Geriatrics, and ${ }^{\mathrm{c}}$ Nephrology, \\ Transplantology and Internal Medicine, Medical University of Gdańsk, Gdańsk, Poland
}

\section{Key Words}

Oxidized low-density lipoprotein • Chronic kidney disease • Paraoxonase-1

\begin{abstract}
Changes mediated by oxidative stress are thought to be involved with atherosclerosis in patients with chronic kidney disease (CKD). The purpose of this study was to analyze the markers of oxidative damage and the activity of antioxidative enzymes as well as the total antioxidant capability in patients with different stages of CKD, both conventionally treated and dialyzed. We evaluated the oxidative modification of lipids (by oxidized low-density lipoprotein and malonodialdehyde levels) and proteins (by advanced oxidation protein products level). We also assessed the activity of paraoxonase- 1 and glutathione peroxidases and total antioxidant status. Compared with the control group, the uremic patients, both dialyzed and nondialyzed, had higher levels of all studied plasma oxidative stress markers and decreased activity of antioxidative enzymes. Our results lead us to conclude that oxidative stress seems to be related rather to the uremic state than to the dialysis treatment. We also showed that estimating total antioxidant status in a simple test is unreliable for assessing the antioxidant ability of patients with CKD.

Copyright $\odot 2010$ S. Karger AG, Basel
\end{abstract}

\section{KARGER}

Fax +41613061234 E-Mail karger@karger.ch www.karger.com (c) 2010 S. Karger AG, Basel

$1420-4096 / 11 / 0341-0012 \$ 38.00 / 0$

Accessible online at:

www.karger.com/kbr

\section{Introduction}

Oxidative stress is known to be involved in many human pathological processes, such as hypertension, atherosclerosis and neurological disorders. Much evidence shows that chronic kidney disease (CKD) is also associated with increased oxidant production and decreased antioxidant defenses [1-5].

It has been suggested that oxidant-antioxidant imbalance is one of the major causes of increased risk of atherosclerosis and cardiovascular disease in patients with chronic renal failure [6-8]. The precise mechanism of CKD-induced oxidative stress has not been completely explained. There are many potential sources of increased oxidative stress in CKD patients: uremic toxins, iron overload, angiotensin 2, proinflammatory cytokines and decreased level of antioxidants [4]. Hemodialysis can be a further cause of oxidative stress development. Neutrophils and the complementary pathway may be activated during hemodialysis with a subsequent increase in the neutrophil free radical production $[9,10]$. Peritoneal dialysis appears to be more physiological than hemodialysis, but its effects on creating oxidative stress have also been described [11].

The important components of antioxidative defense, which can be impaired in CKD patients are antioxidative enzymes such as catalase, glutathione peroxidases, super-

Agnieszka Kuchta

Department of Clinical Chemistry

Medical University of Gdańsk

Dębinki 7, PL-80-220 Gdańsk (Poland)

Tel. +48 5834927 95, Fax +48 5834615 38, E-Mail agastencel@gumed.edu.pl 
oxide dismutases or paraoxonase-1 (PON-1). Glutathione peroxidases $(\mathrm{Gpx})$ are antioxidant enzymes that can detoxify hydroperoxides and lipid hydroperoxides in the presence of reduced glutathione. Several types of Gpx have been identified, 2 of which are cellular Gpx (cGpx) found in blood cells and extracellular Gpx (eGpx) present in plasma. Reduction in eGpx activity in CKD patients is well documented [12]. However, we still need to explain how the type of therapy used influences the eGpx activity and to describe the relationships with other oxidative stress markers.

Even more questions concern cGpx activity. Some authors underline its antiatherogenic properties, but the studies of cGpx activity on CKD patients present unclear results $[12,13]$

Because of the important role in maintaining the prooxidant-antioxidant balance, the activity of peroxidases in different stages of CKD still requires further analysis.

Another component of enzymatic antioxidant defense, especially important in the context of atherosclerosis development risk is PON-1. PON-1 is a high-density lipoprotein (HDL)-associated enzyme which catalyses the breakdown of phospholipid and cholesteryl-ester lipid peroxides, and has been shown to reduce the susceptibility of low-density lipoprotein (LDL) to peroxidation [14]. Oxidized LDL (ox-LDL) is recognized as a key factor in the development of atherosclerosis, leading to the uptake of LDL by the macrophage scavenger receptor and, hence, leading to the formation of foam cells [15]. Apart from ox-LDL, another marker of lipid peroxidation is serum malonodialdehyde (MDA), which is the breakdown product of chain reactions leading to oxidation of polyunsaturated fatty acids.

Another indication of oxidative stress existence is oxidative-mediated protein damage, which can be estimated through measurement of advanced oxidative protein products (AOPP). The level of AOPP in plasma also seems to be important in CKD patients because of its suggested connections with atherosclerotic cardiovascular events [16].

We have many markers which describe the oxidantantioxidant imbalance, but the value of certain factors in renal failure is still unclear. Especially questionable is the estimation of total antioxidant capacity in simple tests such as total antioxidant status (TAS). The purpose of this study was to analyze different oxidative stress markers in patients with different stages of CKD. We analyzed biochemical parameters of kidney function and the influence of the applied therapy on oxidative stress markers and the relationship between measured factors.

\section{Patients and Methods}

\section{Patient Characteristics}

123 patients with CKD and 35 healthy subjects agreed to participate in the study and gave their written consent. The Ethics Committee of the Medical University of Gdańsk approved the study.

46 patients (22 males and 24 females, average age $58 \pm 12$ years) were on peritoneal dialysis (PD), 36 patients ( 25 males and 11 females, average age $59 \pm 11$ years) were on hemodialysis (HD), 41 patients (23 males and 18 females, average age $58 \pm 13$ years) were under conventional treatment (CT) and 35 healthy subjects ( 11 males and 24 females, average age $41 \pm 15$ years) were recruited as a control group.

Patients on maintenance HD were dialyzed 3 times weekly, using polysulfone membrane dialyzers and bicarbonate-buffered dialysate. The time period on dialysis ranged between 6-289 months (24 years), with an average of 74 months ( 6.2 years). The causes of their renal disorders were diabetes mellitus $(n=10)$, glomerulonephritis $(n=5)$, hypertension $(n=5)$, polycystic kidney disease $(n=3)$, nephrosclerosis $(n=2)$ and unknown $(n=11)$.

Patients on PD where dialyzed using Stay Safe solution. The time period on dialysis ranged between $4-138$ months (11.5 years) with an average of 29 months (2.4 years). The causes of their renal disorders were diabetes mellitus $(n=10)$, glomerulonephritis $(n=$ $12)$, hypertension $(n=6)$, pyelonephritis $(n=2)$, nephrosclerosis $(n=1)$, congenital malformations of kidneys $(n=2)$, lupus nephropathy $(n=1)$, cyclosporine-induced nephropathy $(n=1)$ and unknown $(\mathrm{n}=11)$.

The patients receiving CT were divided into 3 subgroups according to the different stages of CKD. 7 patients were in the 3rd stage CKD (moderate reduction in GFR of 30-59 $\mathrm{ml} / \mathrm{min} /$ $1.73 \mathrm{~m}^{2}$ ), 16 patients were in the 4 th stage of CKD (severe reduction in GFR of $15-29 \mathrm{ml} / \mathrm{min} / 1.73 \mathrm{~m}^{2}$ ) and 18 patients were in the 5 th stage of CKD (GFR $<15 \mathrm{ml} / \mathrm{min} / 1.73 \mathrm{~m}^{2}$, i.e. kidney failure). The causes of their renal disorders were diabetes mellitus $(n=10)$, glomerulonephritis $(n=5)$, hypertension $(n=6)$, polycystic kidney disease $(n=3)$, lupus nephropathy $(n=1)$, pyelonephritis $(\mathrm{n}=1), \operatorname{IgA}$ nephropathy $(\mathrm{n}=1)$ and unknown $(\mathrm{n}=14)$.

Individuals with a clinically apparent, active infectious or immunological process; treated with immunosuppressive therapy; or taking antibiotics were not qualified to participate in the study. Patients with LDL $>100 \mathrm{mg} / \mathrm{dl}$ were treatment with angiotensinconverting enzyme inhibitor or/and statins. Blood samples were taken from HD patients immediately before and after the dialysis session and from PD and CT patients, as well as from the control subjects, after overnight fasting. Venous blood was collected in plain vacutainer tubes containing lithium heparin. Plasma was immediately separated from red blood cells by centrifugation (500 $\mathrm{g}$ for $15 \mathrm{~min}$ ) and plasma samples were stored at $-80^{\circ} \mathrm{C}$ until analysis.

\section{Determination of Biochemical Parameters}

Plasma concentrations of creatinine, uric acid, C-reactive protein, total cholesterol, triglycerides, hemoglobin and albumin were determined by standard methods with commercially available kits (Emapol Co., Gdańsk, Poland). HDL fraction was separated by the precipitation method using heparin-mangan reagent and HDL cholesterol was measured by standard enzymatic methods. LDL cholesterol level was calculated using the Friedewald 
Table 1. Characteristic and biochemical parameters of healthy subjects (control group) and CKD patients

\begin{tabular}{|c|c|c|c|c|c|c|c|}
\hline & \multicolumn{7}{|l|}{ Group } \\
\hline & \multicolumn{3}{|l|}{ CT } & \multirow[t]{2}{*}{$\mathrm{PD}$} & \multirow{2}{*}{$\begin{array}{l}\text { HD (before } \\
\text { dialysis) }\end{array}$} & \multirow{2}{*}{$\begin{array}{l}\text { HD (after } \\
\text { dialysis) }\end{array}$} & \multirow[t]{2}{*}{ Control } \\
\hline & $\begin{array}{l}\text { 3rd stage } \\
\text { of CKD }\end{array}$ & $\begin{array}{l}\text { 4th stage } \\
\text { of CKD }\end{array}$ & $\begin{array}{l}\text { 5th stage } \\
\text { of CKD }\end{array}$ & & & & \\
\hline Creatinine, mg/dl & $1.7 \pm 0.3$ & $3 \pm 0.6$ & $5 \pm 1.2$ & $7.3 \pm 2.4$ & $7.8 \pm 2.5$ & $3.4 \pm 0.9$ & $0.73 \pm 0.2$ \\
\hline $\mathrm{eGFR}, \mathrm{ml} / \mathrm{min}$ & $38 \pm 5$ & $22 \pm 4$ & $11 \pm 6$ & - & - & - & $>60$ \\
\hline Albumin, g/l & $42.7 \pm 3$ & $38 \pm 5$ & $36 \pm 6$ & $40 \pm 4.5$ & $41 \pm 7.4$ & $46 \pm 3.4$ & $49 \pm 1.8$ \\
\hline Uric acid, g/dl & $8 \pm 0.9$ & $9 \pm 2$ & $8.8 \pm 1.7$ & $7.7 \pm 1.5$ & $8.3 \pm 1.8$ & $3.6 \pm 1$ & $6.1 \pm 1.4$ \\
\hline $\mathrm{T}-\mathrm{CH}, \mathrm{mg} / \mathrm{dl}$ & $185 \pm 36$ & $186 \pm 33$ & $182 \pm 55$ & $196 \pm 40$ & $167 \pm 46$ & $179 \pm 50$ & $168 \pm 22$ \\
\hline LDL-C, mg/dl & $124 \pm 31$ & $115 \pm 25$ & $119 \pm 50$ & $119 \pm 31$ & $99 \pm 38$ & $107 \pm 39$ & $106 \pm 31$ \\
\hline $\mathrm{TG}, \mathrm{mg} / \mathrm{dl}$ & $170 \pm 90$ & $187 \pm 77$ & $142 \pm 52$ & $197 \pm 32$ & $136 \pm 105$ & $142 \pm 99$ & $80 \pm 47$ \\
\hline HDL-C, mg/dl & $41 \pm 13$ & $35 \pm 11$ & $36 \pm 15$ & $40 \pm 10$ & $43 \pm 2$ & $46 \pm 11$ & $48 \pm 13$ \\
\hline nonHDL-C, mg/dl & $144 \pm 36$ & $151 \pm 29$ & $146 \pm 43$ & $156 \pm 43$ & $124 \pm 49$ & $132 \pm 50$ & $121 \pm 26$ \\
\hline
\end{tabular}

Date are means $\pm \mathrm{SD} . \mathrm{T}-\mathrm{CH}=$ Total cholesterol; LDL-C = low-density lipoprotein cholesterol; HDL-C = high-density lipoprotein cholesterol; $\mathrm{TG}=$ triglycerides.

method. Non-HDL cholesterol was calculated according to the equation: non-HDL cholesterol $=$ total cholesterol - HDL cholesterol. The estimated GFR (eGFR) level was calculated using the MDRD formula.

Determination of Oxidative-Antioxidative Balance Markers

Plasma MDA assay was based on the transformation of chromogen (thiobarbituric acid) to a chromophore after condensation with MDA. The reaction with thiobarbituric acid was performed as previously described [17].

ox-LDL was measured by a sandwich enzyme-linked immunosorbent assay with a commercially available kit (Oxidized LDL Competitive ELISA Kit; Mercodia, Sweden). The method uses monoclonal antibody 4E6 as the capture antibody and anti-human polyclonal antibody for detection.

AOPP were determined in the plasma spectrophotometrically after lipid precipitation, according to the previously described method [18].

TAS was measured using a commercially available kit (TAS; Randox, UK) based on the capacity of plasma antioxidants to suppress the blue-green color of the radical cation $\mathrm{ABTS}^{+}$.

Gpx activity in plasma and in erythrocytes was measured using a commercially available kit (Ransel; Randox). Plasma Gpx (eGpx) activity was measured in plasma, and cGpx activity was measured in hemolysate in which hemoglobin was earlier converted to cyanmethemoglobin. The activity unit of eGpx was expressed as $\mu$ mol NADPH oxidized per minute per liter of plasma, and the activity unit of cGpx was expressed as $\mu \mathrm{mol}$ NADPH oxidized per minute per gram of hemoglobin.

PON-1 activity towards paraoxon was measured after reaction of paraoxon hydrolysis into p-nitrophenol and diethylphosphate catalyzed by the enzyme according to the method described previously [19]. The activity unit of PON-1 was defined as $1 \mu \mathrm{mol}$ of p-nitrophenol formed per minute per liter of plasma.

\section{Statistical Analysis}

Statistical analysis was performed using the Statistica software package (Statistica 8.0; Statsoft, Poland). To establish date distributions, the Shapiro-Wilk test was used. Data analysis was performed using both parametric and nonparametric tests when appropriate. Values are expressed as the mean \pm SD except for PON-1 activity values, which are expressed as the median and range. One-way analysis of variance (ANOVA) was used to determine the significance of differences between more than 2 groups. Comparisons of unpaired data between 2 groups were performed using Student's t test for Gaussian variables and the Mann-Whitney $U$ test for non-Gaussian variables. Pre-HD and post-HD groups were compared using paired Student's t test. Correlation analyses were examined by using Pearson's coefficient or Spearman's coefficient for nonparametric data. $\mathrm{p}<0.05$ was considered statistically significant.

\section{Results}

Characteristics of patients and the control group are categorized by treatment methods as shown in table 1 .

\section{Biomarkers of Lipid Peroxidation (MDA and ox-LDL)}

Plasma MDA and ox-LDL levels were significantly increased in all analyzed groups of patients with CKD compared to the control group (fig. 1a, b). CT patients showed a significant inverse correlation between MDA levels and eGFR values $(\mathrm{r}=-0.42 ; \mathrm{p}=0.007)$, but we did not find such a correlation in the case of ox-LDL. There were also no statistical differences in MDA and ox-LDL levels between nondialyzed patients in the 5th stage of CKD and 

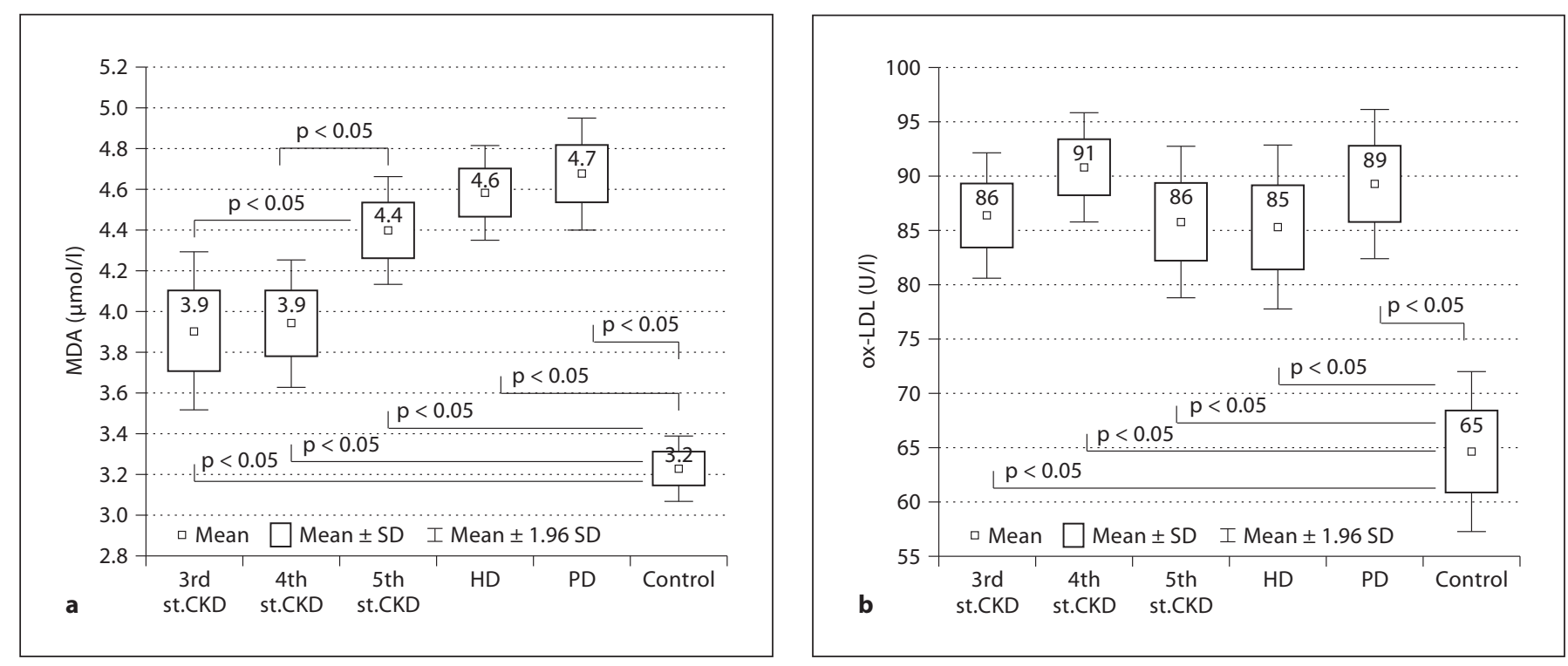

Fig. 1. Plasma MDA (a) and ox-LDL (b) levels in healthy subjects (control) and CKD patients. HD = Hemodialysis (after dialysis); st.CKD = stage of CKD.

dialyzed patients. We also did not find a correlation between plasma MDA or ox-LDL levels with patients age.

Since the HD procedure is connected with loss of water and condensation of undialyzed particles, we corrected the concentration of all analyzed plasma parameters before and after dialysis for the level of albumin as an undialyzed particle. After taking these factors into consideration, we did not find a difference between the results before and after dialysis (table 2).

\section{Biomarkers of Protein Peroxidation (AOPP)}

Plasma AOPP levels were significantly increased in all analyzed groups of patients with CKD compared to the control group (fig. 2).

In CT patients, AOPP levels correlated negatively with eGFR values $(\mathrm{r}=-0.45 ; \mathrm{p}=0.003)$. CT patients in the 5 th stage of CKD had the highest value of AOPP (5.9 \pm 2.1 $\mu \mathrm{mol} / \mathrm{g}$ albumin). The average levels of AOPP did not significantly change during the dialysis session (table 2). Similarly, there was no correlation with patient age.

\section{Activity of Antioxidative Enzymes}

Both dialyzed and nondialyzed patients with CKD showed lower activity of antioxidative enzymes in comparison to the control group (table 3).

Additionally, in CT patients the activity of eGpx decreased gradually with the severity of CKD and correlated negatively with eGFR values $(r=-0.45 ; p=0.003)$.
Table 2. Plasma levels of oxidative stress markers and activity of antioxidative enzymes after correction for albumin level, before and after hemodialysis session

\begin{tabular}{lccc}
\hline & \multicolumn{2}{c}{ Hemodialysis } & $\mathrm{p}$ \\
\cline { 2 - 3 } & before dialysis & after dialysis & \\
\hline $\mathrm{MDA}, \mu \mathrm{mol} / \mathrm{g} \mathrm{Alb}$ & $0.122 \pm 0.02$ & $0.12 \pm 0.02$ & n.s. \\
ox-LDL, U/g Alb & $2.3 \pm 0.63$ & $2.26 \pm 0.64$ & n.s. \\
AOPP, $\mu \mathrm{mol} / \mathrm{g} \mathrm{Alb}$ & $3.9 \pm 1.1$ & $3.9 \pm 1.2$ & n.s. \\
$\mathrm{PON}-1, \mathrm{U} / \mathrm{g} \mathrm{Alb}$ & $3.9(1.4-7.9)$ & $2.8(1.4-7.9)$ & n.s. \\
pGpx, U/g Alb & $2.6 \pm 0.3$ & $2.4 \pm 0.6$ & n.s.
\end{tabular}

The values represented as the means \pm SD or median (range). $\mathrm{Alb}=$ Albumin; n.s. = not significant.

In HD patients, the dialysis procedure did not significantly change the activity of antioxidative enzymes (table 2). There was no correlation between activity of the analyzed enzymes and patients age.

\section{Total Antioxidative Activity (TAS Levels)}

TAS values were significantly higher in comparison to the controls among the CT, PD and HD (before dialysis) patients, but dramatically decreased after the dialysis session (fig. 3). 


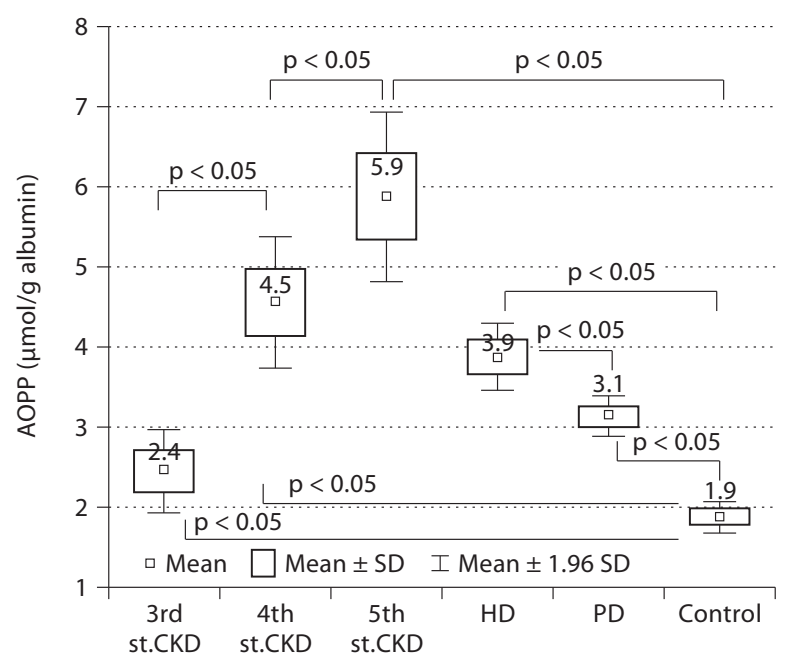

Fig. 2. Plasma AOPP levels in healthy subjects (control) and CKD patients. $\mathrm{HD}=$ Hemodialysis (after dialysis); st.CKD = stage of CKD.

We found a highly significant positive correlation between TAS values and uric acid concentrations in PD, CT and HD (before dialysis) patients, but not in HD (after dialysis) patients ( $\mathrm{r}=0.8, \mathrm{p}=0.001$ for $\mathrm{CT} ; \mathrm{r}=0.4, \mathrm{p}=$ 0.008 for PD; and $\mathrm{r}=0.4, \mathrm{p}=0.02$ for HD before dialysis). We found no significant correlation between TAS values and plasma creatinine levels.

\section{Discussion}

The aim of this study was to analyze the different oxidative stress markers and activity of 2 antioxidative enzymes in patients with different stages of CKD and considered to have a very high risk of cardiovascular disease.

Our findings indicate that the oxidative stress level in uremic patients is correlated with severe and progressive renal failure. The most distinct relationship between the marker of oxidative stress and the degree of renal failure progression was shown when studying eGpx activity. The eGpx activity was slightly decreased in the early stage of CKD and further dramatically decreased in the next stages of renal failure (table 2), which confirms reports published by a number of other groups [12, 20, 21]. This decrease in the eGpx activity may reflect a consequence of active nephron mass reduction and is in keeping with the suggestion that the renal tubule is the main site of

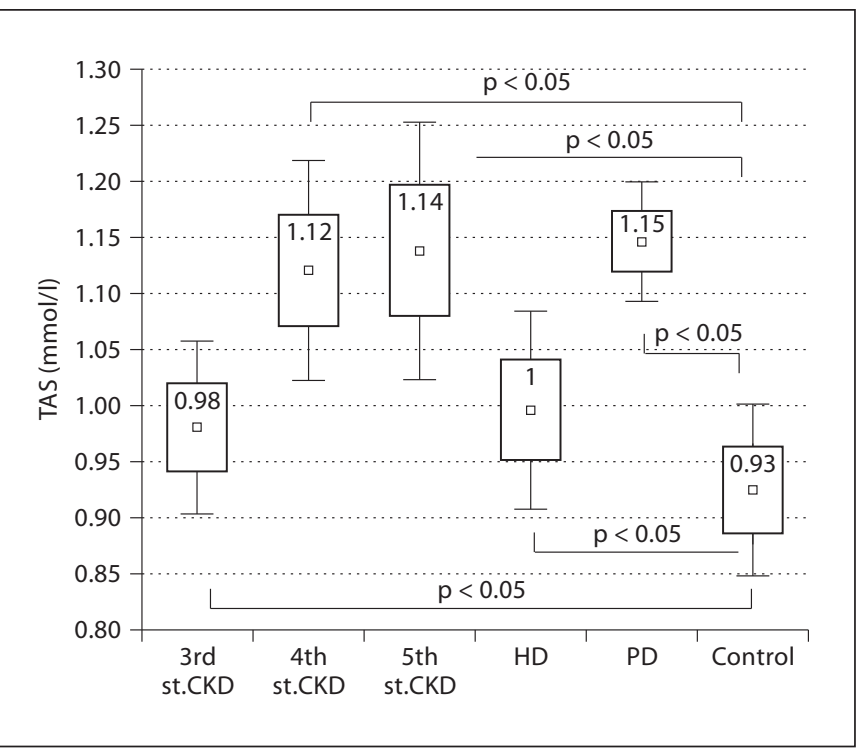

Fig. 3. TAS values in healthy subjects (control) and CKD patients. st.CKD $=$ Stage of CKD.

synthesis of eGpx [22]. There are also other possible reasons for the loss of enzyme activity, such as decreased inactivation of reactive oxygen species due to selenium deficiency as well as lowered renal removal.

The literature on cGpx is controversial. Some authors have shown a significant reduction of cGpx activity in CKD patients [23]. Others have not indicated differences in comparison to the control group [13]. Some researchers have even noted an increase in cGpx activity in CKD patients [12]. We found a slight but significant decrease in cGpx activity in CKD patients, but no relationship with the progression of renal disease was observed (table 3).

Another important parameter for estimating susceptibility to oxidative modifications, especially lipid modifications, is PON-1. PON-1 is an HDL-associated hydrolase, which is able to inhibit lipoprotein oxidation. We observed decreased PON-1 activity in each stage of CKD, compared to the control (table 3). Additionally, we noticed gradually decreased $\mathrm{PON}-1$ activity in the next stages of CKD, but the differences between particular stages of CKD did not reach statistical significance (table 3). The causes of reduced enzyme activity are unclear. Experimental studies show that it is possible to inactivate the enzyme by uremic toxins, including reaction products of ROS such as AOPP [24]. The reduced activity of PON-1 can also be caused by a modification of HDL and its instability, which has been shown earlier $[25,26]$. 
Table 3. Activity of antioxidative enzymes in healthy subjects (control group) and CKD patients

\begin{tabular}{|c|c|c|c|c|c|c|c|}
\hline & \multirow{3}{*}{$\begin{array}{l}\text { Control } \\
\text { group }\end{array}$} & \multicolumn{6}{|l|}{ Patients } \\
\hline & & \multicolumn{3}{|l|}{$\mathrm{CT}$} & \multirow[t]{2}{*}{$\mathrm{PD}$} & \multicolumn{2}{|l|}{$\mathrm{HD}$} \\
\hline & & $\begin{array}{l}\text { 3rd stage } \\
\text { of CKD }\end{array}$ & $\begin{array}{l}\text { 4th stage } \\
\text { of CKD }\end{array}$ & $\begin{array}{l}\text { 5th stage } \\
\text { of CKD }\end{array}$ & & before & after \\
\hline eGpx, U/l & $164 \pm 15$ & $153 \pm 13$ & $138 \pm 21^{*}$ & $125 \pm 15^{*, \wedge, \#}$ & $97 \pm 16^{*}$ & $98 \pm 10^{*}$ & $100 \pm 12^{*}$ \\
\hline cGpx, U/gHb & $66 \pm 11$ & $55 \pm 15^{*}$ & $56 \pm 11^{*}$ & $58 \pm 14$ & $59 \pm 15^{*}$ & $59 \pm 12^{*}$ & $60 \pm 11$ \\
\hline PON-1, U/1 & $170(71-454)$ & $122(83-277)$ & $123^{*}(65-256)$ & $105^{*}(51-250)$ & $100 *(35-297)$ & $120 *(39-290)$ & $110^{*}(38-290)$ \\
\hline
\end{tabular}

The values are represented as the means \pm SD or median (range) depending on their parametric or nonparametric distribution. * Significant differences between patients and control group. ${ }^{\wedge}$ Significant differences between CT patients in 5th stage of CKD and PD patients. ${ }^{*}$ Significant differences between CT patients in 5th stage of CKD and HD (after dialysis) patients.

The phenomenon of the drop in eGpx and PON-1 activity might additionally account for the increased lipid peroxidation and consequently, for the further increase in atherosclerosis risk.

We indicated that in comparison to the controls, CKD patients had higher levels of MDA and ox-LDL (fig. 1a, b), both of which are markers of lipid peroxidation.

Some authors skeptically refer to MDA weight as an oxidative stress marker [27]; however, our results (fig. 1a) are in line with a previous study postulating an association between MDA levels and prevalent cardiovascular disease [28], and confirm the significance of these biomarkers in uremic patients.

Levels of ox-LDL may be also associated with the presence of atherosclerosis, which has been shown in both renal and nonrenal patients $[29,30]$. Some studies reported significant differences in ox-LDL levels between uremic patients and the control group [31], but others did not show such differences [32]. In our study, ox-LDL levels, although higher in uremic patients compared to the control group, did not show alterations in patients in different stages of CKD (fig. 1b).

In tandem with oxidized lipid parameters, the impact of oxidized proteins on atherosclerosis development has recently been studied extensively. Dityrosine containing oxidation protein products, e.g. AOPP, have been proposed as a relevant marker of oxidative protein damage, which may be related to atherosclerosis risk in uremic patients [16]. AOPP are considered not only as a simple marker of oxidative protein damage, but their role in accelerating oxidative processes has also been documented [33]. The in vitro study demonstrated that AOPP were capable of triggering the oxidative burst of human mono- cytes and neutrophils, thus they may by themselves contribute to the inflammatory process in CKD [34]. In our study, we measured the concentration of AOPP after precipitation of lipids in order to avoid overestimated data due to lipid interferences. We found that AOPP levels corrected for albuminemia were much increased in CKD patients and negatively correlated with GFR $(r=-0.6 ; \mathrm{p}<$ $0.001)$.

It is worth emphasizing that we concurrently determined the various parameters of oxidative stress, of which the level of AOPP seems to be the strongest indicator showing growth of free radical modification in CKD patients.

The above-mentioned results showed that uremia per se may induce a state of oxidative stress, but some authors have suggested that the oxidative-antioxidative imbalance may be also enhanced by dialysis treatment. HD treatment could impose additional oxidative stress due to the bioincompatibility of dialyzer membranes and the activation of macrophages, as well as the potential presence of toxins in dialysis fluid. PD appears to be more physiological than HD, but its effect on creating oxidative stress has also been demonstrated [11]. Our results show that the greatest impact on the development of oxidative stress is the severity of renal failure. However, dialysis methods are not neutral for oxidant-antioxidant balance and their impact on particular oxidative processes is multifaceted and still requires further investigation.

We did not find significant differences in PON-1, cGpx activity and ox-LDL levels between patients with end-stage renal disease (5th stage of CKD) and dialyzed patients (see Results). Higher eGpx activity in nondialyzed patients (table 2) may be explained by residual 
nephron function and the ability to synthesize the enzyme in this group of patients.

The highest levels of AOPP in predialyzed patients were surprising and in contrast to earlier studies $[35,36]$, which showed a lower level of AOPP in nondialyzed patients with advanced renal failure compared to dialyzed patients. On the other hand, some authors [37] reported a drop in AOPP levels while monitoring patients before the start of PD and after 6 and 12 months of treatment. Therefore, the question whether dialysis in the final stadium of CKD is able to decrease protein susceptibility to oxidative modifications demands further investigation. A comparison of the results obtained before and after HD showed no significant differences in the measured parameters after including the possibility of a condensation infiltrative element of plasma and the corrected obtained value for albuminemia. This indicates that the HD procedure has no noticeable direct effect on oxidative stress parameters.

We also tried to estimate the total antioxidative ability of plasma by using the common method of TAS. These tests showed that uremic patients have paradoxically higher overall plasma antioxidant activity (fig. 3). However, the higher than normal TAS values decreased during dialysis. We also found a good correlation of TAS val- ues with uric acid levels in PD and CT patients, as well as patients on HD before the dialysis session. These observations showed that increased TAS values seem to be dependent mainly on increased uric acid levels, which explains the lower test results in the control group. In vitro experiments have shown uric acid to be a powerful scavenger of reactive oxygen species [38]; however, hyperuricemia is an accepted risk factor and marker of chronic cardiovascular disease $[39,40]$; therefore, the TAS test which is influenced by uric acid seems to be an unreliable method for assessing the antioxidant capacity of patients with CKD. These findings additionally emphasize that in order to avoid false conclusions, the proper choice of method for describing oxidative stress is very important.

In conclusion, our findings indicate that uremic patients have both higher levels of all studied plasma oxidative stress markers and a decreased activity of antioxidative enzymes, indicating greater vulnerability of these patients to oxidative-antioxidative imbalance. In particular, AOPP level and pGpx activity are the main parameters associated with the progression of renal failure. Hopefully, further investigation of oxidative stress markers in CKD patients will allow us to define the potential target for interrupting the vicious circle of kidney disease and cardiovascular complications.

\section{References}

1 Tylicki L, Rutkowski B, Horl WH: Antioxidants: a possible role in kidney protection. Kidney Blood Press Res 2003;26:303-314.

-2 Araujo M, Welch WJ: Oxidative stress and nitric oxide in kidney function. Curr Opin Nephrol Hypertens 2006;15:72-77.

-3 Przekwas M, Malgorzewicz S, Zdrojewski Z, et al: Influence of predialysis oxidative stress on peroxidation processes after renal transplantation. Transplant Proc 2003;35:21702173.

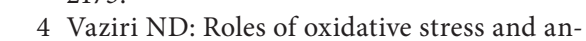
tioxidant therapy in chronic kidney disease and hypertension. Curr Opin Nephrol Hypertens 2004;13:93-99.

-5 Rutkowski P, Malgorzewicz S, Slominska E, et al: Interrelationship between uremic toxicity and oxidative stress. J Ren Nutr 2006;16: 190-193.

-6 Kitiyakara C, Gonin J, Massy Z, Wilcox CS: Non-traditional cardiovascular disease risk factors in end-stage renal disease: oxidate stress and hyperhomocysteinemia. Curr Opin Nephrol Hypertens 2000;9:477-487.
7 Himmelfarb J, Stenvinkel P, Ikizler TA, Hakim RM: The elephant in uremia: oxidant stress as a unifying concept of cardiovascular disease in uremia. Kidney Int 2002;62: 1524-1538.

-8 Oberg BP, McMenamin E, Lucas FL, et al: Increased prevalence of oxidant stress and inflammation in patients with moderate to severe chronic kidney disease. Kidney Int 2004;65:1009-1016.

-9 Himmelfarb J, Lazarus JM, Hakim R: Reactive oxygen species production by monocytes and polymorphonuclear leukocytes during dialysis. Am J Kidney Dis 1991;17: 271-276.

10 Ward RA, McLeish KR: Oxidant stress in hemodialysis patients: what are the determining factors? Artif Organs 2003;27:230-236.

-11 Samouilidou EC, Grapsa EJ, Kakavas I, et al: Oxidative stress markers and C-reactive protein in end-stage renal failure patients on dialysis. Int Urol Nephrol 2003;35:393-397.

12 Ceballos-Picot I, Witko-Sarsat V, MeradBoudia M, et al: Glutathione antioxidant system as a marker of oxidative stress in chronic renal failure. Free Radic Biol Med 1996;21: 845-853.
13 Ozden M, Maral H, Akaydin D, et al: Erythrocyte glutathione peroxidase activity, plasma malondialdehyde and erythrocyte glutathione levels in hemodialysis and CAPD patients. Clin Biochem 2002;35:269-273.

14 Getz GS, Reardon CA: Paraoxonase, a cardioprotective enzyme: continuing issues. Curr Opin Lipidol 2004;15:261-267.

15 Wang Y, Fang X, Wang S, et al: Relation between plasma oxLDL antibodies and oxLDL in the circulation. Inflammation 2007;30:713.

16 Kaneda H, Taguchi J, Ogasawara K, et al: Increased level of advanced oxidation protein products in patients with coronary artery disease. Atherosclerosis 2002;162:221-225.

17 Wilson DW, Metz HN, Graver LM, Rao PS: Direct method for quantification of free malondialdehyde with high-performance capillary electrophoresis in biological samples. Clin Chem 1997;43:1982-1984.

$\checkmark 18$ Anderstam B, Ann-Christin BH, Valli A, et al: Modification of the oxidative stress biomarker AOPP assay: application in uremic samples. Clin Chim Acta 2008;393:114-118. 
-19 MacKness B, Mackness MI, Durrington PN, et al: Paraoxonase activity in two healthy populations with differing rates of coronary heart disease. Eur J Clin Invest 2000;30:410.

-20 Zachara BA, Wlodarczyk Z, Andruszkiewicz J, et al: Glutathione and glutathione peroxidase activities in blood of patients in early stages following kidney transplantation. Ren Fail 2005;27:751-755.

-21 Zachara BA, Salak A, Koterska D, et al: Selenium and glutathione peroxidases in blood of patients with different stages of chronic renal failure. J Trace Elem Med Biol 2004;17: 291-299.

-22 Avissar N, Ornt DB, Yagil Y, et al: Human kidney proximal tubules are the main source of plasma glutathione peroxidase. Am J Physiol 1994;266:C367-C375.

23 Zachara BA, Trafikowska U, Adamowicz A, et al: Selenium, glutathione peroxidases, and some other antioxidant parameters in blood of patients with chronic renal failure. J Trace Elem Med Biol 12001;5:161-166.

24 Sutherland WH, de Jong SA, Walker RJ: Hypochlorous acid and low serum paraoxonase activity in haemodialysis patients: an in vitro study. Nephrol Dial Transplant 2004;19:7582.

-25 Schiavon R, Battaglia P, De Fanti E, et al: HDL3-related decreased serum paraoxonase (PON) activity in uremic patients: comparison with the PON1 allele polymorphism. Clin Chim Acta 2002;324:39-44.
26 Schiavon R, De Fanti E, Giavarina D, et al: Serum paraoxonase activity is decreased in uremic patients. Clin Chim Acta 1996;247: 71-80.

27 Palleschi S, De Angelis S, Diana L, et al: Reliability of oxidative stress biomarkers in hemodialysis patients: a comparative study. Clin Chem Lab Med 2007;45:1211-1218.

28 Boaz M, Matas Z, Biro A, et al: Serum malondialdehyde and prevalent cardiovascular disease in hemodialysis. Kidney Int 1999;56: 1078-1083.

29 Yoshimura S, Suemizu H, Nomoto Y, et al: Plasma glutathione peroxidase deficiency caused by renal dysfunction. Nephron 1996; 73:207-211.

30 Holvoet P, Harris TB, Tracy RP, et al: Association of high coronary heart disease risk status with circulating oxidized LDL in the well-functioning elderly: findings from the Health, Aging, and Body Composition Study. Arterioscler Thromb Vasc Biol 2003; 23:1444-1448.

-31 Takenaka T, Takahashi K, Kobayashi T, et al: Oxidized low density lipoprotein (Ox-LDL) as a marker of atherosclerosis in hemodialysis (HD) patients. Clin Nephrol 2002;58:3337.

-32 Diepeveen SH, Verhoeven GH, van der Palen $\mathrm{J}$, et al: Oxidative stress in patients with endstage renal disease prior to the start of renal replacement therapy. Nephron Clin Pract 2004;98:c3-c7.

33 Liu SX, Hou FF, Guo ZJ, et al: Advanced oxidation protein products accelerate atherosclerosis through promoting oxidative stress and inflammation. Arterioscler Thromb Vasc Biol 2006;26:1156-1162.
34 Witko-Sarsat V, Friedlander M, Nguyen Khoa $\mathrm{T}$, et al: Advanced oxidation protein products as novel mediators of inflammation and monocyte activation in chronic renal failure. J Immunol 1998;161:2524-2532.

-35 Witko-Sarsat V, Friedlander M, CapeillereBlandin C, et al: Advanced oxidation protein products as a novel marker of oxidative stress in uremia. Kidney Int 1996;49:1304-1313.

$>36$ Capeillere-Blandin C, Gausson V, Nguyen AT, et al: Respective role of uraemic toxins and myeloperoxidase in the uraemic state. Nephrol Dial Transplant 2006;21:15551563.

>37 Boulanger E, Moranne O, Wautier MP, et al: Changes in glycation and oxidation markers in patients starting peritoneal dialysis: a pilot study. Perit Dial Int 2006;26:207-212.

-38 Ames BN, Cathcart R, Schwiers E, Hochstein P: Uric acid provides an antioxidant defense in humans against oxidant- and radicalcaused aging and cancer: a hypothesis. Proc Natl Acad Sci USA 1981;78:6858-6862.

39 Verdecchia P, Schillaci G, Reboldi G, et al: Relation between serum uric acid and risk of cardiovascular disease in essential hypertension. The PIUMA study. Hypertension 2000; 36:1072-1078.

40 Capasso G, Jaeger P, Robertson WG, Unwin RJ: Uric acid and the kidney: urate transport, stone disease and progressive renal failure. Curr Pharm Des 2005;11:4153-4159. 